\title{
Revelation of mRNAs and proteins in porcine milk exosomes by transcriptomic and proteomic analysis
}

Ting Chen ${ }^{1+}$, Qian-Yun $\mathrm{Xi}^{1+}$, Jia-Jie Sun ${ }^{1}$, Rui-Song Ye ${ }^{1}$, Xiao Cheng ${ }^{1}$, Rui-Ping Sun ${ }^{1,2}$, Song-Bo Wang ${ }^{1}$, Gang Shu', Li-Na Wang ${ }^{1}$, Xiao-Tong Zhu' ${ }^{1}$, Qing-Yan Jiang ${ }^{1}$ and Yong-Liang Zhang ${ }^{1 *}$

\begin{abstract}
Background: Milk is a complex liquid that provides nutrition to newborns. Recent reports demonstrated that milk is enriched in maternal-derived exosomes that are involved in fetal physiological and pathological conditions by transmission of exosomal mRNAs, miRNAs and proteins. Until now, there is no such research relevant to exosomal mRNAs and proteins in porcine milk, therefore, we have attempted to investigate porcine milk exosomal mRNAs and proteins using RNA-sequencing and proteomic analysis.
\end{abstract}

Results: A total of 16,304 (13,895 known and 2,409 novel mRNAs) mRNAs and 639 (571 known, 66 candidate and 2 putative proteins) proteins were identified. GO and KEGG annotation indicated that most proteins were located in the cytoplasm and participated in many immunity and disease-related pathways, and some mRNAs were closely related to metabolisms, degradation and signaling pathways. Interestingly, 19 categories of proteins were tissuespecific and detected in placenta, liver, milk, plasma and mammary. COG analysis divided the identified mRNAs and proteins into 6 and 23 categories, respectively, 18 mRNAs and 10 proteins appeared to be involved in cell cycle control, cell division and chromosome partitioning. Additionally, 14 selected mRNAs were identified by qPCR, meanwhile, 10 proteins related to immunity and cell proliferation were detected by Western blot.

Conclusions: These results provide the first insight into porcine milk exosomal mRNA and proteins, and will facilitate further research into the physiological significance of milk exosomes for infants.

Keywords: Porcine milk exosomes, RNA-seq, Proteomic analysis

\section{Background}

Milk is the primary source of nutrition for newborns, and breastfeeding is known to make a valuable contribution to infant health [1]. Breast milk contains a potent mixture of diverse components including milk fat globules (MFG), immune competent cells, antibodies, soluble proteins, cytokines, and antimicrobial peptides [2] that together protect young infants against infections [3]. In addition, the milk contains growth factors which could

\footnotetext{
*Correspondence: zhangyl@scau.edu.cn

${ }^{\dagger}$ Equal contributors

${ }^{1}$ National Engineering Research Center For Breeding Swine Industry, Guandong Provincial Key Laboratory of Agro-Animal Genomics and Molecular Breeding, Guandong Province Research Center of Woody Forage Engineering and Technology, South China Agricultural University, 483 Wushan Road, Guangzhou 510642, China

Full list of author information is available at the end of the article
}

promote intestinal development [4] and may protect infants against developing allergies [5]. Meanwhile, milk also contain many microvesicles, such as milk-derieved exosomes, who was reported to transfer contained RNAs to living cells and influenced the development of calf's gastrointestinal and immune systems [6].

Exosomes are small membrane vesicles $(30-100 \mathrm{~nm})$ which released from producing cells into the extracellular environment [7]. Many different cell types have the capacity to produce and release exosomes [8-13]. Additionally, milk-derived exosomes have been reported in humans, cows and pigs [14-17] and which involved in many biological processes. Exosomes contain proteins, mRNAs, miRNAs and lipids. Recent studies revealed that human [18], bovine [19], pig [20], and rat [21] milk contain miRNAs, and mRNAs have also been identified in 
whey [6, 21-23]. 10,948 mRNA transcripts were detected in rat milk, and some immune and development-related mRNAs showed time-dependent expression [21]. 19,320 mRNAs were detected by microarray analyses in bovine milk exosomes, and they had possible effects of human cells [24]. Additionally, Cecilia Lässer et al. demonstrated that mRNAs in breast milk exosomes could be taken up by human macrophages [25].Until now, the components of mRNAs in porcine milk exosmes are still unclear.

Proteins in exosome were dependented on the specific cell-type [26], the dendritic cell-derived exosomes contain several cytosolic proteins [8]. Body fluid derived exosomes CD24, CD9, Annexin-1 and Hsp70 were as positive marker proteins [27]. Anti-MHC-class II- and anti-CD63 beads were used to isolate human breast milk exosmes [28]. In bovine milk exosomes 2,107 proteins were identified, and all major exosome protein markers were abundant [29], as were milk fat globule membrane (MFGM) proteins. Another report showed 2,350 proteins in bovine milk exosome via iTRAQ, and 90 exosomal proteins were found to be differentially regulated by infections [30].

In our previous study, miRNAs in porcine milk exosomes have been revealed by deep sequencing [17], but up to now, porcine milk exosomal mRNAs and proteins remains unknown. Therefore, we further performed RNA-sequencing and proteomic analysis of porcine milk exosomes in order to understand new physiological functions, especially immunity and proliferation related regulation of porcine milk.

\section{Methods}

\section{Milk sample preparation}

Fresh porcine milk samples were collected from 10 healthy Landrace female pigs that had been lactating for 1 to 5 days (after parturition) at the pig farm of the South China Agriculture University (Guangzhou, China). Milk samples were frozen immediately and kept at $-80{ }^{\circ} \mathrm{C}$ until used.

\section{Isolation of milk exosomes}

Porcine milk exosomes were separated as previously described [17]. Briefly, about $80-100 \mathrm{~mL}$ fresh raw porcine milk samples were centrifuged at 2,000 g for $30 \mathrm{~min}$ at $4{ }^{\circ} \mathrm{C}$ to remove milk fat globules (MFGs) and mammary gland-derived cells [18]. Defatted samples were then subjected to centrifugation at $12,000 \mathrm{~g}$ for $30 \mathrm{~min}$ at $4{ }^{\circ} \mathrm{C}$ to remove residual MFGs, casein, and other debris [6]. From the supernatant, the membrane fraction was prepared by ultracentrifugation at $110,000 \mathrm{~g}$ for $2 \mathrm{~h}$ using an SW41T rotor (Beckman Coulter Instruments, Fullerton, CA). Then, the exosome purification steps were as previously described $[29,30]$.

\section{RNA isolation}

Total RNA was isolated from porcine milk exosome samples by Trizol reagent (Invitrogen, Carlsbad, CA) according to the manufacturer's protocol. The quality of RNA was examined by $2 \%$ agarose gel electrophoresis and with a BiophotometerNanoDrop 2000 (Thermo, USA), as well as further confirmed using a Bioanalyzer (Agilent Technologies, Santa Clara, CA).

\section{RNA-sequencing}

The collected RNA samples were analyzed by IlluminaHiSeq $^{\text {TM }} 2000$ analyzer at Beijing Genomics Institute(BGI, Shenzhen, China) as previously described [31]. Firstly, poly (A) mRNA was isolated from total RNA sample with Oligo(dT) magnetic beads. Secondly, the purified mRNA was fragmented by the RNA fragmentation kit (Ambion), the first-strand cDNA synthesis was performed using random hexamer primers and reverse transcriptase, and the second-strand cDNA was synthesized using RNase $\mathrm{H}$ and DNA polymerase I. Then the cDNA libraries were prepared using the Illumina Genomic DNA Sample Prep kit (Illumina) following the manufacturer's protocol. Finally, the library was sequencing using Illumina HiSeq 2000.

\section{Sequencing analysis}

The porcine reference genome sequence and annotated transcript set were downloaded from the ensemble database (Sscrofa10.2, http://asia.ensembl.org/Sus_scrofa/ Info/Index). After quality control (QC) step of raw reads, then removing low quality reads, reads containing Ns $>5$ and reads containing adapters, clean reads were aligned to the reference pig genomic database (Sscrofa 10.2,) with SOAPaligner/SOAP2 [32] and allowing up to 5 mismatches in 90-bp reads. The alignment data were utilized to calculate distribution of reads on pig gene database (http://www.ncbi.nlm.nih.gov/), and the numbers of reads per kilobase of dexon region in a gene per million mapped reads were used as the value of normalized gene expression levels [33]. The unalignment data carried out novel transcript prediction, reads are at least 200 bp away from annotated gene, the transcript is of length over180 bp and the sequencing depth is no less than 2 for novel transcript unit analysis.

\section{qPCR identification of known mRNAs in porcine milk exosome}

Total RNA (identical with the RNA-sequencing sample) was first digested with DNase I (Promega, American), and $2 \mu \mathrm{g}$ of total RNA was reverse transcribed by oligo (dT). The cDNA was diluted by 2 -fold with $\mathrm{ddH}_{2} \mathrm{O}$, and PCR was performed on a Bio-Rad system (BIO-RAD, USA) in a final $20 \mu \mathrm{L}$ volume reaction, containing $2 \mu \mathrm{L}$ PCR cDNA, $10 \mu \mathrm{L}$ of $2 \times$ PCR 
Mix (Roche, Switzerland) and $1 \mathrm{mM}$ of each primer. The real-time PCR thermal profile was as follows: $5 \mathrm{~min}$ at $95{ }^{\circ} \mathrm{C}, 40$ cycles of $30 \mathrm{~s}$ at $94{ }^{\circ} \mathrm{C}, 30 \mathrm{~s}$ at the corresponding annealing temperature $(\mathrm{Tm})$ and $72{ }^{\circ} \mathrm{C}$ for $30 \mathrm{~s}$, followed by $72{ }^{\circ} \mathrm{C}$ at $10 \mathrm{~min}$, and $5 \mathrm{~S}$ ribosomal RNA was used as an internal control for the PCR [17, 34]. The mRNAs primers were designed with Primer 5.0 (Table 1).

\section{Total protein extraction}

RIPA lysis buffer was used to extract porcine milk exosomal proteins according to the assay kit protocol (Bioteke, Beijing). Briefly, $1 \mathrm{mM}$ PMSF was added to the RIPA lysis buffer and $100-200 \mu \mathrm{L}$ was added to porcine milk exosomes. Following complete exosome lysis, the sample was centrifuged at $10,000-14,000 \mathrm{~g}$ for $3-5 \mathrm{~min}$ and the supernatant was subjected to further analysis. Proteins were stored at $-80{ }^{\circ} \mathrm{C}$ until used.

\section{Protein separation by 1D SDS-PAGE and in-gel digestion}

Porcine milk exosome proteins were resolved by $12 \%$ polyacrylamide gel. The gel was stained with Coomassie blue R-250. 20 bands were excised and destained using $50 \mathrm{mM}$ ammonium bicarbonate in $50 \% \mathrm{ACN}$. And then the gel pieces were performed incubating with $10 \mathrm{mM}$ DTT in $25 \mathrm{mM}$ ammonium bicarbonate for $1 \mathrm{~h}$ at $60{ }^{\circ} \mathrm{C}$ to reduce disulfide bonds and incubating the samples with $55 \mathrm{mM}$ iodoacetamide in $25 \mathrm{mM}$ ammonium bicarbonate for $45 \mathrm{~min}$ at room temperature in dark for $\mathrm{Al}$ kylation of cysteines. Then, using the Trypsin Gold (Promega, Madison, WI, USA) for digested $\left(37{ }^{\circ} \mathrm{C}, 16 \mathrm{~h}\right.$ ) the gel bands. After the peptides sequentially extracted

Table 1 Primers for $\mathrm{QPCR}$

\begin{tabular}{|c|c|c|c|}
\hline ID & Primer & Sequences (5'to3') & Products length (bp) \\
\hline \multirow[t]{2}{*}{ ENSSSCG00000000207 } & LOC100739053-F & CAAAGGAAGCCTACAAGAA & \multirow[t]{2}{*}{198} \\
\hline & LOC100739053-R & CACGGTAGTCCAGCAGA & \\
\hline \multirow[t]{2}{*}{ ENSSSCG00000003930 } & RPS8-F & GAGAAAGCCCTACCACA & \multirow[t]{2}{*}{191} \\
\hline & RPS8-R & CGTCAATAATCCTCGTCT & \\
\hline \multirow[t]{2}{*}{ ENSSSCG00000004489 } & EF1ALPH-F & GATTGTTGCTGCTGGTGT & \multirow[t]{2}{*}{226} \\
\hline & EF1ALPH-R & TGCTACTGTATCAGGGTTGT & \\
\hline \multirow[t]{2}{*}{ ENSSSCG00000004177 } & RPS12-F & TCTACCCGTAACCCACC & \multirow[t]{2}{*}{219} \\
\hline & RPS12-R & CCTCCACCAACTTGACATA & \\
\hline \multirow[t]{2}{*}{ ENSSSCG00000015103 } & RPS25-F & GCCCAAGGACGACAA & \multirow[t]{2}{*}{109} \\
\hline & RPS25-R & GCCTTTGGACCACTTC & \\
\hline \multirow[t]{2}{*}{ ENSSSCG00000006249 } & RPS20-F & ACCGCTGTTCGCTCTTC & \multirow[t]{2}{*}{211} \\
\hline & RPS20-R & GTCCCTTCACTTTGAGGTTCT & \\
\hline \multirow[t]{2}{*}{ ENSSSCG00000029830 } & RPL8-F & CGAGCGACACGGCTACAT & \multirow[t]{2}{*}{255} \\
\hline & RPL8-R & GGCTTCTCCTCCAGACAACAC & \\
\hline \multirow[t]{2}{*}{ ENSSSCG00000009267 } & CSN3-F & CACCTGAGACCACCACT & \multirow[t]{2}{*}{140} \\
\hline & CSN3-R & TGACTGAAGGCAGATAA & \\
\hline \multirow[t]{2}{*}{ ENSSSCG00000013907 } & UBA52-F & ACGGGCAAGACCATCAC & \multirow[t]{2}{*}{196} \\
\hline & UBA52-R & GCAGACGAAGCACCAAGT & \\
\hline \multirow[t]{2}{*}{ ENSSSCG00000001502 } & RPS18-F & AGGGTGTAGGACGGAGAT & \multirow[t]{2}{*}{134} \\
\hline & RPS18-R & CTTGTATTGGCGAGGATT & \\
\hline \multirow[t]{2}{*}{ ENSSSCG00000024825 } & RPL6-F & CAGAGGCAAGAGGGTCA & \multirow[t]{2}{*}{128} \\
\hline & RPL6-R & TGGTGGAGGTGGCAATA & \\
\hline \multirow[t]{2}{*}{ ENSSSCG00000004970 } & RPLP1-F & GCACGACGATGAGGTTAC & \multirow[t]{2}{*}{131} \\
\hline & RPLP1-R & TGAGGCTCCCGATGTT & \\
\hline \multirow[t]{2}{*}{ ENSSSCG00000010328 } & RPS24-F & TTGATGTCCTTCACCCTG & \multirow[t]{2}{*}{269} \\
\hline & RPS24-R & CATTCTGTTCTTGCGTTCT & \\
\hline \multirow[t]{2}{*}{ ENSSSCG00000025527 } & FABP3-F & GCTGGGATTGAAGTTTGA & \multirow[t]{2}{*}{163} \\
\hline & FABP3-R & GTGGGTGAGTGTCAGGATG & \\
\hline \multirow[t]{2}{*}{$5 S$} & $5 S-F$ & TCTACGGCCATACCACCCTGAA & \multirow[t]{2}{*}{83} \\
\hline & $5 S-R$ & GGCCCGACCCTGCTTAG & \\
\hline
\end{tabular}


from gel bands by $0.1 \%$ formic acid in $50 \%$ ACN twice, using $100 \%$ ACN twice, the extracted peptides were dried and stored at $-80{ }^{\circ} \mathrm{C}$ until LC-MS/MS analysis.

\section{Protein sequencing}

Protein samples were analyzed using a Q-EXACTIVE mass spectrometer at the Beijing Genomics Institute (BGI, Shenzhen, China). Briefly, samples were separated by $1 D$ SDS-PAGE and in-gel digestion was performed to generate peptides for LC-MS/MS analysis. Peptide fractions were initially separated on a LC-20 AD nanoHPLC (Shimadzu, Kyoto, Japan), then subjected to nanoelectrospray ionization followed by tandem mass spectrometry (MS/MS) using a Q EXACTIVE (ThermoFisher Scientific, San Jose, CA) coupled online to the HPLC.

\section{LC-ESI-MS/MS analysis based on Q EXACTIVE}

After a series of processing, we regulated each fraction at the average final concentration of peptide at $0.5 \mu \mathrm{g} / \mathrm{uL}$ and loading $10 \mathrm{uL}$ on a LC-20 AD nanoHPLC (Shimadzu, Kyoto, Japan) by the autosampler onto a $2 \mathrm{~cm}$ C18 trap column. Then $10 \mathrm{~cm}$ analytical C18 column (inner diameter $75 \mu \mathrm{m}$ ) was used for eluted the peptides. After the sample was loading to the trap column, then bring into the analytical column, and finally the separated peptides were subjected to nanoelectrospray ionization followed by tandem mass spectrometry (MS/ MS) in a Q EXACTIVE (ThermoFisher Scientific, San Jose, CA) coupled online to the HPLC. Resolution of 7,000 on Orbitrap was used to detect the intact peptides. Peptides were selected for MS/MS using high-energy collision dissociation (HCD) operating mode with a normalized collision energy setting of 27.0; ion fragments were setting of a resolution of 17,500. A data-dependent procedure that alternated between one MS scan followed by $15 \mathrm{MS} / \mathrm{MS}$ scans was applied for the 15 most abundant precursor ions above a threshold ion count of 20,000 in the MS survey scan with a following Dynamic Exclusion duration of $15 \mathrm{~s}$. The electrospray voltage applied was $1.6 \mathrm{kV}$. The Automatic gain control (AGC) which used to optimize the spectra generated by the orbitrap was target for full MS was $3 \mathrm{e} 6$ and 1e5 for MS2. For MS scans, the $\mathrm{m} / \mathrm{z}$ scan range was 350 to 2,000 Da. For MS2 scans, the $\mathrm{m} / \mathrm{z}$ scan range was 100 1,800. All those works were carried out in Beijing Genomics Institute (BGI, Shenzhen, China).

\section{Protein data analysis}

All raw data were acquired using an Orbitrap, converted to MGF files using Proteome Discoverer 1.2 (PD1.2, Thermo), and the Mascot search engine (Matrix Science, London, UK; version 2.3.02) was used to search against a database containing 25,152 sequences(ftp://ftp.ensembl.org/pub/release-73/fasta/sus_scrofa/pep/).Non-intact $\quad(>20 \quad \mathrm{ppm})$ peptides and fragmented ions ( $0.6 \mathrm{Da}$ ) were removed, with allowance for one missed cleavage in trypsin digests. Next, the fixed carbamidomethyl $(\mathrm{C})$ modification, and potential variable modifications Gln- > pyro-Glu (N-term Q), oxidation $(\mathrm{M})$, deamidation $(\mathrm{NQ})$, and +2 and +3 charge states were considered. Mascot was used to search the automatic decoy database by choosing the decoy checkbox, with the decoy checkbox set to generate a random sequence of database and test for raw spectra, as well as the actual database. Finally, only peptides with significance scores $\geq 20$ at the 99\% confidence interval in the Mascot probability analysis were counted as identified proteins [29]. All identified proteins included at least one unique peptide.

\section{Western blot identification}

Protein samples $(20-30 \mu \mathrm{g})$ were measured by BCA assay [35], and separated using 10-15\% SDS-PAGE, transferred to a $0.22 \mu \mathrm{m}$ or $0.45 \mu \mathrm{m}$ polyvinylidenedifluoride membrane (Millipore), and incubated with specific and HRPconjugated secondary antibodies, and detected with an enhanced chemiluminescence kit (Roche, Switzerland) using FluorChem M (Proteinsimple) [36]. Anti-EGF (AB20578b), anti-TGFB-3 (AB20578b), anti-MSTN (AB60418a), connective tissue growth factor (CTGF) (AB60212a), antiPDGFA (AB61078b), anti-CD63 (D260973), anti-IGFBP-7 (AB60509b), anti-CD9 (AB54118), anti-HTRA3 (AB61337a), and anti-THBS1 (AB61391a) were purchased from BBI Antibody (SangonBiotch, Shanghai, China). Lactoferrin $(C-15)$ and $\beta$-actin were purchased from Santa Cruz (Santa Cruz, American). Protein' concentrations were determined using the Pierce BCA Protein Assay Kit (Thermo Fisher, American) using a BSA standard.

\section{Bioinformatics analysis}

We performed functional annotation using Blast2GO to search the non-redundant protein database (NR; NCBI) and the COG database (http://www.ncbi.nlm.nih.gov/ COG/), which was used to classify and group the identified proteins. All the known mRNAs and proteins were performed Gene Ontology, KEGG pathway and Tissuespecific using DAVID6.7 bioinformatics resources (http://david.abcc.ncifcrf.gov/).

\section{Results}

Identification of exosomes by western blotting and extraction of RNA and protein from porcine milk exosome We previously isolated exosomes from porcine milk and analyzed them using transmission electron microscopy [17]. In the present study, we observed exosomal marker proteins CD63 and CD9 by Western blotting (Fig. 1a). We extracted total RNA from the pellets after ultracentrifugation and examined the RNA by Agilent 2100, and the results showed that the porcine milk exosome contained RNAs and small rRNAs (Fig. 1c), which is consistent with 
$\mathbf{a}$

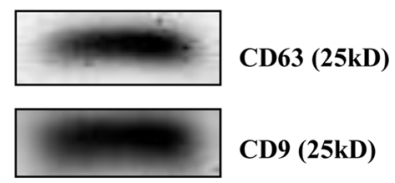

c

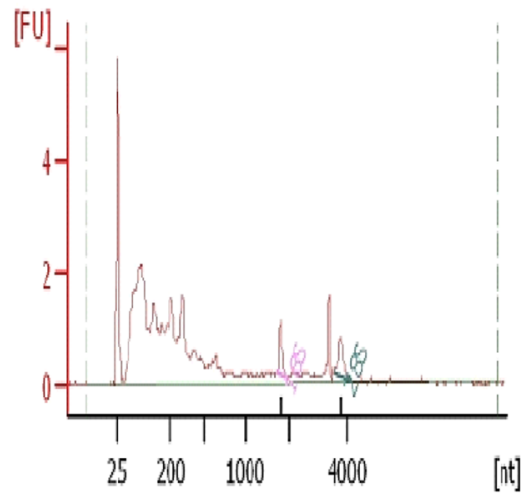

b

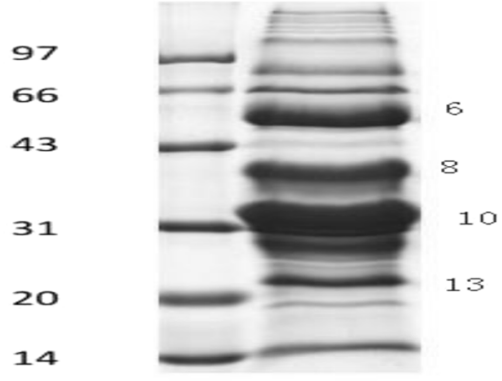

d

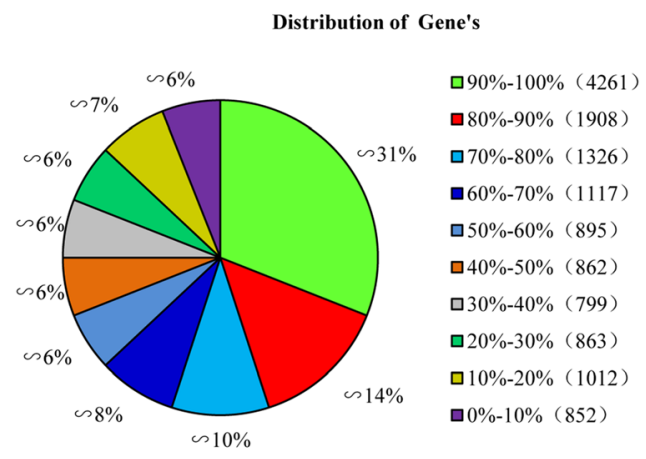

Fig. 1 Identification of proteins and mRNAs in porcine milk exosomes. a detection of the exosomal marker proteins CD63 and CD9 by Western blotting. b SDS-PAGE. c RNA sample analyzed by the Agilent Bioanalyzer 2100. d distribution of genen's coverage

previous studies $[4,6,17,20]$. Porcine milk proteins were extracted using RIPA lysis buffer and resolved using SDSPAGE (Fig. 1b), which proteins covered a large molecular weight range, but most of them were fell into the 20-25, $28-35,35-40$ and $43-55 \mathrm{kDa}$ ranges, and these ranges were considered separately.

\section{Transcript sequencing and analysis}

\section{Transcript sequencing}

We totally obtained $77,106,888$ raw reads, which mapped to porcine genome (sscrofa10.2, www.ensembl.org/Sus_scrofa/). The mapped proportion was $63.76 \%$ accounting for $49,161,814$ reads, and the perfect match reads were $33,863,808$ (43.92\%) and the unique match reads were $45,080,932$ (58.47\%). By blast searching the 77,106,888 reads against pig coding gene database (http:// www.ncbi.nlm.nih.gov/), 57,413,016 total match reads (represented 74.46\%) and 53,836,128 (69.82\%) unique matched reads were identified (Table 2). All the reads represent 13,895 genes (Additional file 1), the subsequent distribution of genes' coverage analysis showed the number of genes' coverage $>50 \%$ contained 9,507 genes and represented $69 \%$ of 13,895 genes, the 4,261 (representing $31 \%$ ) genes coverage are $90 \%-100 \%$ (Fig. 1d).

Table 2 Alignment statistics of RNA-seq data map to reference genome and gene database

\begin{tabular}{|c|c|c|c|c|}
\hline & \multicolumn{2}{|c|}{ Map to Genome } & \multicolumn{2}{|l|}{ Map to Gene } \\
\hline & Reads number & Percentage & Reads number(control) & Percentage \\
\hline Total Reads & $77,106,888$ & $100.00 \%$ & $77,106,888$ & $100.00 \%$ \\
\hline Total Base Pairs & $6,939,619,920$ & $100.00 \%$ & $6,939,619,920$ & $100.00 \%$ \\
\hline Total Mapped Reads & $49,161,814$ & $63.76 \%$ & $57,413,016$ & $74.46 \%$ \\
\hline perfect match & $33,863,808$ & $43.92 \%$ & $45,400,239$ & $58.88 \%$ \\
\hline$<=5$ bp mismatch & $15,298,006$ & $19.84 \%$ & $12,012,777$ & $15.58 \%$ \\
\hline unique match & $45,080,932$ & $58.47 \%$ & $53,836,128$ & $69.82 \%$ \\
\hline multi-position match & $4,080,882$ & $5.29 \%$ & $3,576,888$ & $4.64 \%$ \\
\hline Total Unmapped Reads & $27,945,074$ & $36.24 \%$ & $19,693,872$ & $25.54 \%$ \\
\hline
\end{tabular}




\section{Novel mRNAs predicted in pig exosome milk}

Then we performed a novel transcript prediction and annotation according to the criteria described in Method. Results showed we obtained 2,409 novel transcripts (Fig. 2a and Additional file 2), and those novel transcripts were distributed in all the 19 chromosomes. These results would improve the gene annotations of the porcine genome and transcriptome [31].

\section{qPCR identified for mRNAs}

After a series of analysis of RNA sequencing, we randomly selected 14 transcripts genes from the top 50 list (Additional file 3) for evaluated their expression in the porcine milk exosomes by qPCR. The results showed that they were all detected in the sample (Fig. 2b).

\section{Proteome sequencing and data analysis}

Following separation by SDS-PAGE, in-gel digestion was performed and peptides were analyzed by mass spectroscopy. The four groups of P130340_6, P130340_8, P130340_10 and P130340_13 (6, 8, 10, and 13 in Fig. 1b) were corresponding to $43-55,35-40,28-35$ and $20-$ $25 \mathrm{kDa}$, respectively, which were treated identically, since they displayed a relatively high gray density in the gel. With a false discovery rate (FDR) setting $\leq 1.2 \%$, 307,390 total spectras were detected, which only 18,638 spectras could be mapped using the Mascot software, and 2,313 peptides represent 639 proteins were ultimately identified from the sample (Sus_scrofa, Table 3 and Additional file 4), and which number of protein matched with a given quality match check criterion with at least possessing one unique peptide can be considered as a reliable protein. Of these, 571 proteins were present in the Sscrofa 10.2 database, 66 were novel candidate proteins and two were putative proteins (Additional file 4).
Most of the novel proteins (44) and the two putative proteins were not highly abundant, whereas most of high abundance proteins were known proteins. Analysis of protein and peptide length distribution after digestion revealed that most were between 8 and 54 amino acids, and the majorities were between 9 and 25 residues, with the highest proportion (12\%) comprising 13 amino acids (Additional file 5: Figure S1). Analysis of the peptide and spectrogram distribution showed that lots of proteins were represented by between 1 and 10 unique peptides, and one unique peptide was the predominantly case (Additional file 6: Figure S2). In the sequence coverage range of $0 \%$ to $20 \%, 473$ proteins were identified (77.02\%, Additional file 7: Figure S3e), and the sequence coverage was increased as the number of identified proteins decreased (Additional file 7: Figure S3a, b, c, d, e).

\section{Identification by Western blotting}

Based on the above results, we randomly selected 10 proteins to confirm their presence in porcine milk exosomes. Specifically, EGF, TGF $\beta-3$, MSTN, CTGF, IGFBP7, PDGFA, HTRA3, THBS1, $\beta$-actin and lactoferrin (LTF) were all successfully detected (Fig. 3).

\section{COG annotation of $m R N A s$ and proteins}

The Cluster of Orthologous Groups of proteins (COG) database was used for protein orthologous classification, and all proteins in this database are assumed to be derived from a common protein ancestor. COG analysis showed that proteins from porcine milk exosomes were connected with multiple biological processes (Fig. 4 and Additional file 8). Interestingly, proteins involved in DNA or RNA synthesis and transport particularly abundant. Furthermore, five proteins were related to intracellular trafficking, secretion, and vesicular transport, with some in the high
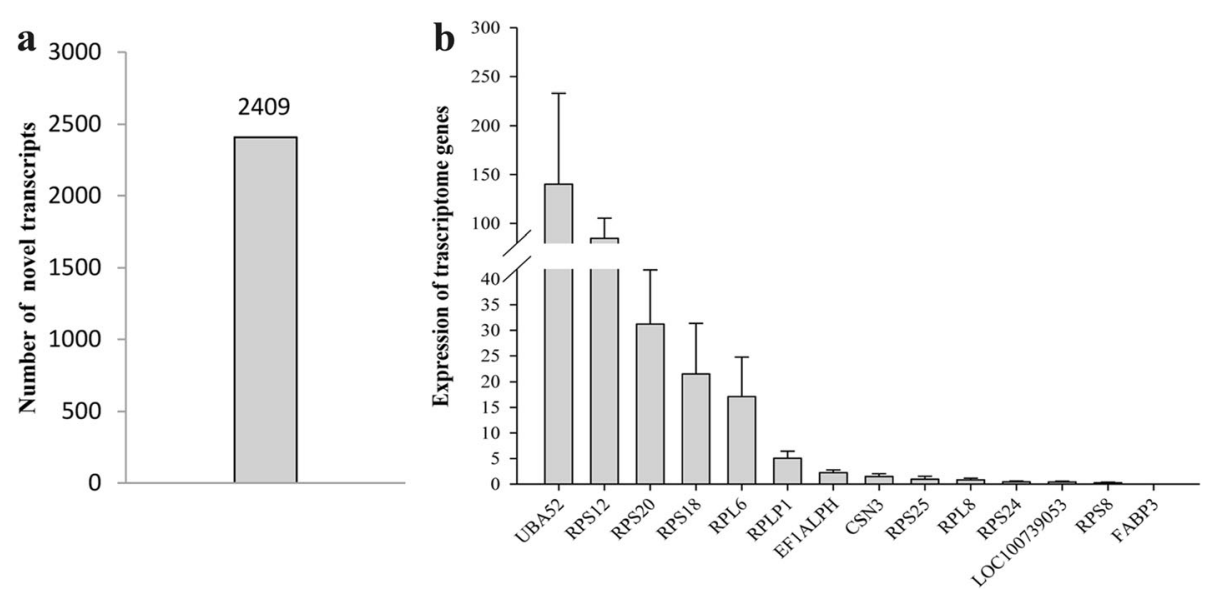

Fig. 2 Statistics of novel transcripts and GPCR detected randomly from top 50 list in RNA-sequencing. a The number of predicted novel transcripts in porcine milk exosome. $\mathbf{b}$ The expression of 14 mRNAs, from left to right, respectively: UBA52, RPS12, RPS20, RPS18, RPL6, RPLP1, EF1ALPH, CSN3, RPS25, RPL8, RPS24, LOC100739053, RPS8, FABP3 
Table 3 Proteins identified in this study

\begin{tabular}{llllllll}
\hline Sample & Total spectra & Identified spectra & Identified peptides & Identified proteins & FDR (\%) & Unknown protein & Putative protein \\
\hline P130340_10 & 13,430 & $672[5.0037 \%]$ & 92 & 40 & 1.05 & 4 & \\
P130340_13 & 17,281 & $790[4.5715 \%]$ & 108 & 44 & 0.90 & 2 & 12 \\
P130340_6 & 17,783 & $721[4.0544 \%]$ & 303 & 94 & 1.13 & 1.03 & 4 \\
P130340_8 & 15,140 & $596[3.9366 \%]$ & 180 & 59 & 1.04 & 66 & 2 \\
Sus_scrofa & 307,390 & $18,638[6.0633 \%]$ & 2,313 & 639 & & \\
\hline
\end{tabular}

abundance P130340_13 (Additional file 9: Figure S4b) and P130340_8 groups (Additional file 9: Figure S4d). Additionally, 10 conserved proteins were involved in cell cycle control, cell division and chromosome partitioning. Similarly, enriched 6 COG Ontology in mRNAs, including 31 genes related to intracellular trafficking and secretion and 18 mRNAs of Cell division and chromosome partitioning / Cytoskeleton (Fig. 5 and Additional file 10).

\section{Go analysis of mRNAs and proteins}

GO annotation was performed using DAVID version 6.7 (http://david.abcc.ncifcrf.gov) with a standard Benjamini $<0.05$. We selected the top $10 \mathrm{GO}$ terms of Cellular Component (CC), Molecular Function (MF) and Biological Process (BP) for further analysis. For mRNA, cytoplasm genes account for a high proportion (6.3\%), and specific intracellular organelle lumen, nuclear lumen genes account for $\sim 1.9 \%$. Predicted functions included various bindings (including adenyl ribonucleotide, magnesium ion, nuclear hormone receptor and protein kinase) and diverse enzymatic activity (including protein kinase, pyrophosphate, transcription coactivator, exonuclease, small conjugating protein ligase and NADH dehydrogenase), predicted biological processes relative to proteins (include protein metabolic, transport, modification and catabolic process) and RNA (including RNA metabolic, processing and ncRNA processing) (Table 4

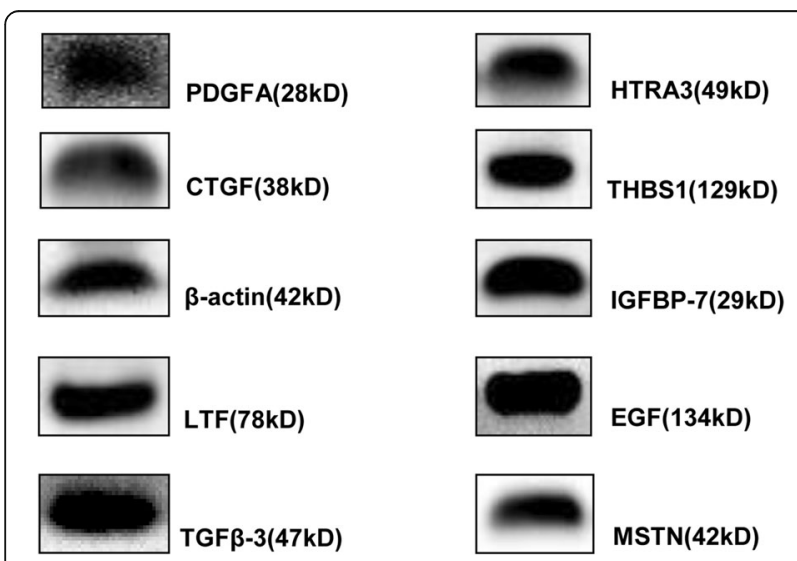

Fig. 3 Confirmation by Western blotting. All 10 randomly selected proteins were confirmed to be present in porcine milk exosome and Additional file 10). For proteins, most of them were included in cytoplasm and cytoplasmic part, taking a proportion of $7.1 \%$. Additionally, there were lots of specific membrane-bounded vesicle lumen, granule lumen, vesicle, lytic vacuole and reticulum lumen proteins. And major of those proteins were enriched in the molecular function in terms of diverse activity and predicted biological processes, including acute inflammatory response, complement activation, classical pathway, B cell mediated immunity, negative regulation of blood coagulation and coagulation, activation of immune response and protein maturation and processing (Table 5 and Additional file 5).

\section{Tissues-specific analysis of mRNAs and proteins}

All the known mRNAs and proteins were performed tissues-specific analysis. The results of mRNA analysis showed 8,605 of 13,895 genes were associated with 100 tissues, and were significantly correlated (Benjamini $<0.05$ ) with 50 tissues. According to gene number, the top 5 ranking tissues were brain (3,987 genes), placenta $(1,872$ genes), epithelium (1,595 genes), lung (1,426 genes) and liver (1,110 genes) (Table 6 and Additional file 10). However, all the proteins were correlated with 33 tissues, and significantly correlated (Benjamini $<0.05$ ) with only 19 tissues, including the components closely relative tissues of milk, such as plasma, blood, milk and mammary gland. More interestingly, the top five enriched tissues were liver (138 proteins), placenta (128 proteins), skin (75 proteins), lung (74 proteins) and plasma (73 proteins), and the highly correlated tissues were plasma, liver and milk (Table 7 and Additional file 8). These results suggest that mRNAs and proteins in porcine milk exosomes may have originated from multiple tissues.

\section{KEGG pathway analysis of mRNAs and proteins}

Due to the incomplete porcine bioinformatics resources in software DAVID [30], we selected the human database as reference. For mRNA, only 8,605 of 13,895 genes were enriched in 63 KEGG pathways, and the top 20 pathways were involved in various substance metabolisms, degradation, signaling pathway and some diseases pathways. Interestingly, we got 83 genes in cell cycle pathways (Fig. 6a and Additional file 10). For proteins, 

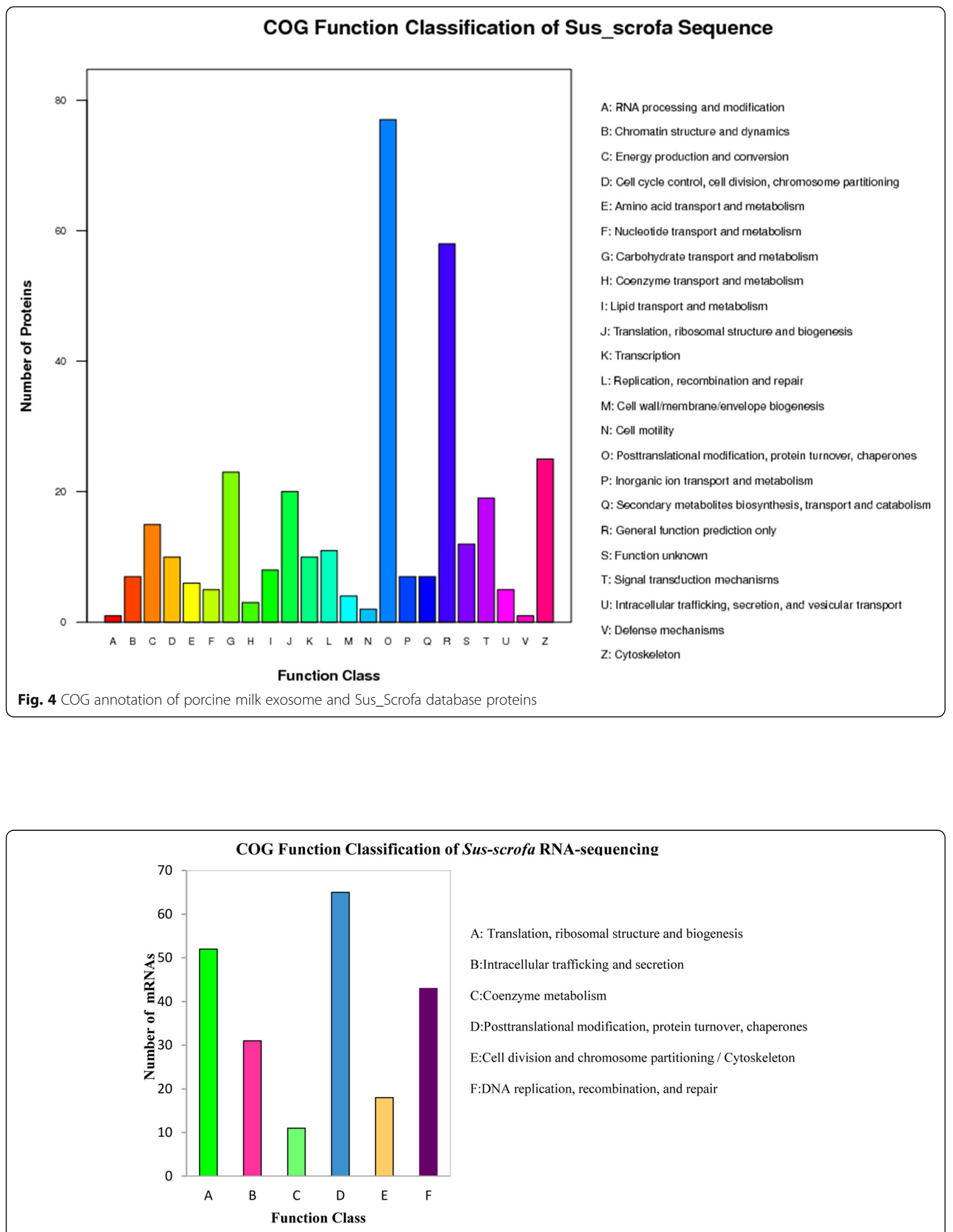

Fig. 5 COG annotation of porcine milk exosome and Sus_Scrofa database mRNAs 
Table 4 GO annotation of identified mRNAs

\begin{tabular}{|c|c|c|c|c|}
\hline Category & Term & Count & $\%$ & Benjamini \\
\hline GOTERM_BP_5 & GO:0044267 cellular protein metabolic process & 1,481 & 1.30 & $2.054 \mathrm{E}-42$ \\
\hline GOTERM_BP_5 & GO:0015031 protein transport & 531 & 0.47 & $3.262 \mathrm{E}-27$ \\
\hline GOTERM_BP_5 & GO:0016070 RNA metabolic process & 633 & 0.56 & $5.403 \mathrm{E}-27$ \\
\hline GOTERM_BP_5 & GO:0006396 RNA processing & 388 & 0.34 & 1.149E-21 \\
\hline GOTERM_BP_5 & GO:0006464 protein modification process & 888 & 0.78 & 8.933E-18 \\
\hline GOTERM_BP_5 & GO:0006886 intracellular protein transport & 271 & 0.24 & 1.149E-16 \\
\hline GOTERM_BP_5 & GO:0030163 protein catabolic process & 404 & 0.36 & $3.782 \mathrm{E}-12$ \\
\hline GOTERM_BP_5 & GO:0043632 modification-dependent macromolecule catabolic process & 374 & 0.33 & 1.875E-11 \\
\hline GOTERM_BP_5 & GO:0044257 cellular protein catabolic process & 390 & 0.34 & $2.34 \mathrm{E}-11$ \\
\hline GOTERM_BP_5 & GO:0034470 ncRNA processing & 141 & 0.12 & 4.795E-10 \\
\hline GOTERM_CC_5 & GO:0005737 cytoplasm & 4,253 & 3.74 & 1.54E-126 \\
\hline GOTERM_CC_5 & GO:0043231 intracellular membrane-bounded organelle & 4,485 & 3.94 & 5.61E-99 \\
\hline GOTERM_CC_5 & GO:0044444 cytoplasmic part & 2,924 & 2.57 & $9.8 \mathrm{E}-86$ \\
\hline GOTERM_CC_5 & GO:0044446 intracellular organelle part & 2,530 & 2.22 & $5.426 \mathrm{E}-71$ \\
\hline GOTERM_CC_5 & GO:0070013 intracellular organelle lumen & 1,200 & 1.06 & $3.933 \mathrm{E}-66$ \\
\hline GOTERM_CC_5 & GO:0044428 nuclear part & 1,205 & 1.06 & $6.521 \mathrm{E}-59$ \\
\hline GOTERM_CC_5 & GO:0031981 nuclear lumen & 979 & 0.86 & $5.556 \mathrm{E}-53$ \\
\hline GOTERM_CC_5 & GO:0005829 cytosol & 879 & 0.77 & $2.958 \mathrm{E}-41$ \\
\hline GOTERM_CC_5 & GO:0005634 nucleus & 2,801 & 2.46 & $1.904 \mathrm{E}-33$ \\
\hline GOTERM_CC_5 & GO:0005654 nucleoplasm & 599 & 0.53 & $2.982 \mathrm{E}-32$ \\
\hline GOTERM_MF_5 & GO:0032559 adenyl ribonucleotide binding & 892 & 0.78 & $1.822 \mathrm{E}-20$ \\
\hline GOTERM_MF_5 & GO:0004672 protein kinase activity & 387 & 0.34 & 1.894E-13 \\
\hline GOTERM_MF_5 & GO:0000287 magnesium ion binding & 294 & 0.26 & $2.071 \mathrm{E}-11$ \\
\hline GOTERM_MF_5 & GO:0016462 pyrophosphatase activity & 448 & 0.39 & $1.642 \mathrm{E}-08$ \\
\hline GOTERM_MF_5 & GO:0035257 nuclear hormone receptor binding & 64 & 0.06 & $1.128 \mathrm{E}-07$ \\
\hline GOTERM_MF_5 & GO:0003713 transcription coactivator activity & 147 & 0.13 & 1.259E-07 \\
\hline GOTERM_MF_5 & GO:0004527 exonuclease activity & 45 & 0.04 & 1.407E-05 \\
\hline GOTERM_MF_5 & GO:0019787 small conjugating protein ligase activity & 108 & 0.09 & 0.0010606 \\
\hline GOTERM_MF_5 & GO:0019901 protein kinase binding & 95 & 0.08 & 0.0050729 \\
\hline GOTERM_MF_5 & GO:0050136 NADH dehydrogenase (quinone) activity & 34 & 0.03 & 0.0085249 \\
\hline
\end{tabular}

the results showed that only 426 of the 571 proteins (known proteins) were found to be enriched using KEGG pathway in the database. These 426 proteins were enriched in 20 pathways (Fig. 6b and Additional file 8), most associated with immunity and diseases.

\section{Discussions}

In the present study, we totally obtained 13,895 known genes and 2,409 putative novel genes in porcine milk exosomes. It was reported 10,948 mRNA transcripts in rats whey [21] and 19,320 transcripts in bovine milk whey exosome by mRNA microarray. Moreover, in human milk, 14,070 transcripts were found in fat globules [37]. Some of milk protein genes (CSN2, CSN3 and CSN1S1), ribosome-related proteins genes (RPS18, RPL18 and RPLP1) and other genes (e.g UBA52, FABP3 and EEF1A1) were highly expressed in the previous researches [21,37], which were in accordance with this study (Additional file 3). Furthermore, some genes such as LALBA, TPT1, SPP1 and FASN were not found in rats whey [21], bovine milk whey exosome and human milk fat globules [37]. Additionally, the randomly selected 14 mRNAs among top 50 were further confirmed using qRT-PCR. Differences of mRNAs in milk or milk exosome exist among species, possibly indicating different functions of milk among species.

One of the aims in the present study was to explore the protein content of porcine milk exosomes using proteomics. In the present study, we observed 639 proteins (Fig. 1b) including the exosomal marker proteins CD9 [38] and CD63 [39] using Western blotting (Fig. 1a), as well as the heat shock protein family members HSPA 90 
Table $\mathbf{5} \mathrm{GO}$ annotation of identified proteins

\begin{tabular}{|c|c|c|c|c|}
\hline Category & Term & Count & $\%$ & Benjamini \\
\hline GOTERM_BP_5 & GO:0002526 acute inflammatory response & 28 & 0.47 & $1.7 \mathrm{E}-17$ \\
\hline GOTERM_BP_5 & GO:0006956 complement activation & 15 & 0.25 & 1.06E-09 \\
\hline GOTERM_BP_5 & GO:0016485 protein processing & 20 & 0.33 & $1.93 \mathrm{E}-08$ \\
\hline GOTERM_BP_5 & GO:0030193 regulation of blood coagulation & 13 & 0.22 & 2.19E-08 \\
\hline GOTERM_BP_5 & GO:0006958 complement activation, classical pathway & 12 & 0.20 & $2.2 \mathrm{E}-08$ \\
\hline GOTERM_BP_5 & GO:0030195 negative regulation of blood coagulation & 11 & 0.18 & $2.31 \mathrm{E}-08$ \\
\hline GOTERM_BP_5 & GO:0051604 protein maturation & 21 & 0.35 & 2.32E-08 \\
\hline GOTERM_BP_5 & GO:0050819 negative regulation of coagulation & 11 & 0.18 & $8.73 \mathrm{E}-08$ \\
\hline GOTERM_BP_5 & GO:0019724 B cell mediated immunity & 14 & 0.23 & 2.36E-07 \\
\hline GOTERM_BP_5 & GO:0002253 activation of immune response & 16 & 0.27 & $2.8 \mathrm{E}-06$ \\
\hline GOTERM_CC_5 & GO:0044444 cytoplasmic part & 190 & 3.16 & 4.07E-16 \\
\hline GOTERM_CC_5 & GO:0005737 cytoplasm & 242 & 4.03 & $1.58 \mathrm{E}-14$ \\
\hline GOTERM_CC_5 & GO:0060205 cytoplasmic membrane-bounded vesicle lumen & 17 & 0.28 & $8.44 \mathrm{E}-14$ \\
\hline GOTERM_CC_5 & GO:0031093 platelet alpha granule lumen & 16 & 0.27 & $4.9 \mathrm{E}-13$ \\
\hline GOTERM_CC_5 & GO:0016023 cytoplasmic membrane-bounded vesicle & 42 & 0.70 & 1.43E-09 \\
\hline GOTERM_CC_5 & GO:0031410 cytoplasmic vesicle & 44 & 0.73 & 1.16E-08 \\
\hline GOTERM_CC_5 & GO:0030141 secretory granule & 22 & 0.37 & 3.97E-08 \\
\hline GOTERM_CC_5 & GO:0048770 pigment granule & 16 & 0.27 & 5.49E-08 \\
\hline GOTERM_CC_5 & GO:0000323 lytic vacuole & 23 & 0.38 & $9.38 \mathrm{E}-08$ \\
\hline GOTERM_CC_5 & GO:0005788 endoplasmic reticulum lumen & 15 & 0.25 & 1.04E-07 \\
\hline GOTERM_MF_5 & GO:0004867 serine-type endopeptidase inhibitor activity & 19 & 0.32 & 5.63E-09 \\
\hline GOTERM_MF_5 & GO:0004252 serine-type endopeptidase activity & 20 & 0.33 & 2.61E-06 \\
\hline GOTERM_MF_5 & GO:0008236 serine-type peptidase activity & 21 & 0.35 & $3.68 \mathrm{E}-06$ \\
\hline GOTERM_MF_5 & GO:0004175 endopeptidase activity & 31 & 0.52 & $3.8 \mathrm{E}-06$ \\
\hline GOTERM_MF_5 & GO:0008201 heparin binding & 15 & 0.25 & $2.18 \mathrm{E}-05$ \\
\hline GOTERM_MF_5 & GO:0005509 calcium ion binding & 51 & 0.85 & $2.98 \mathrm{E}-05$ \\
\hline GOTERM_MF_5 & GO:0004869 cysteine-type endopeptidase inhibitor activity & 7 & 0.12 & 0.010385 \\
\hline GOTERM_MF_5 & GO:0051920 peroxiredoxin activity & 4 & 0.07 & 0.02113 \\
\hline
\end{tabular}

B1, HSPA13, HSPA5, HSPA 9, HSPB1 and HSPCB (Additional file 4), which have been reported in previous exosome research $[7,8,16]$. The Western blotting results in our study confirmed that we successfully isolated porcine milk exosomes. Previous study using iTRAQ identified 2,971 milk proteins with 2,350 from exosomes, 1,012 from MFGM, and 748 from whey (FDR $=0.1 \%$ ) [30], another study found 2,107 proteins in bovine milk exosomes, including the major exosomal marker proteins lactadherin/MFGE8 and TSG 101 (FDR $=0.05 \%$ for proteins and $0.2 \%$ for peptides) [29], the actin family members ACTC1, ACTN1, ACTN2, and ACTN4 are cell-specific proteins likely involved in exosome biogenesis and potentially other exosome functions [7], which were also present in porcine milk exosomes. However, xanthine oxidase $(\sim 147 \mathrm{kDa})$, Butyrophilin $(\sim 59 \mathrm{kDa})$, lactadherin/MGF8 ( 47 kDa) and adipophilin/perilipin-2 $(\sim 49 \mathrm{kDa})$ and MFGM were identified in bovine milk exosomes $[29,40]$, which were not detected in porcine milk exosomes. It has also been suggested that exosomes from different sources might contain different components [16] and may play tissue-specific roles in intracellular communication and immune function [41-43].

In COG ontology analysis of mRNAs and proteins, we obtained 10 conserved proteins and 18 mRNAs relative to cell cycle. Additionally, many genes and proteins involved in cell cycle and immunity related pathways by KEGG pathways analysis. Then, we randomly selected 10 proteins for Western blotting analysis. Plateletderived growth factor (PDGF) acts as a potential binding pattern mitogen for mesenchymal cells both in vitro and in vivo [44]. Epidermal growth factor (EGF) plays an important role in regulating cell proliferation and differentiation during development [45]. Thrombospondin1 (THBS1), cysteine-rich protein 61 (Cyr61) and connective tissue growth factor (CTGF) were all involved in the 
Table 6 mRNAs expressed in a tissue-specific manner

\begin{tabular}{|c|c|c|c|c|}
\hline Category & Term & Count & $\%$ & Benjamini \\
\hline UP_TISSUE & Epithelium & 1,595 & 1.40 & $1.77 E-68$ \\
\hline UP_TISSUE & Placenta & 1,872 & 1.65 & $2.06 \mathrm{E}-44$ \\
\hline UP_TISSUE & Skin & 1,079 & 0.95 & $1.66 \mathrm{E}-38$ \\
\hline UP_TISSUE & Uterus & 1,021 & 0.90 & $4.31 E-35$ \\
\hline UP_TISSUE & Brain & 3,987 & 3.51 & $5.68 \mathrm{E}-34$ \\
\hline UP_TISSUE & Lung & 1,426 & 1.25 & $1.43 \mathrm{E}-28$ \\
\hline UP_TISSUE & Cervix carcinoma & 255 & 0.22 & $3.19 \mathrm{E}-19$ \\
\hline UP_TISSUE & Muscle & 492 & 0.43 & $7.94 \mathrm{E}-18$ \\
\hline UP_TISSUE & Liver & 1,110 & 0.98 & $9.72 \mathrm{E}-16$ \\
\hline UP_TISSUE & Lymph & 400 & 0.35 & $1.43 \mathrm{E}-13$ \\
\hline UP_TISSUE & Fetal brain cortex & 153 & 0.13 & $2.22 \mathrm{E}-13$ \\
\hline UP_TISSUE & Eye & 582 & 0.51 & $4.51 \mathrm{E}-13$ \\
\hline UP_TISSUE & Platelet & 338 & 0.30 & $4.58 \mathrm{E}-13$ \\
\hline UP_TISSUE & Bone marrow & 431 & 0.38 & $4.91 \mathrm{E}-13$ \\
\hline UP_TISSUE & Cervix & 308 & 0.27 & 7.3E-13 \\
\hline UP_TISSUE & Cajal-Retzius cell & 137 & 0.12 & $3.21 \mathrm{E}-11$ \\
\hline UP_TISSUE & Colon & 642 & 0.56 & $1.35 \mathrm{E}-10$ \\
\hline UP_TISSUE & Urinary bladder & 137 & 0.12 & 1.06E-09 \\
\hline UP_TISSUE & B-cell lymphoma & 93 & 0.08 & 7.21E-09 \\
\hline UP_TISSUE & Colon carcinoma & 124 & 0.11 & 7.39E-09 \\
\hline UP_TISSUE & T-cell & 199 & 0.17 & $2.83 \mathrm{E}-08$ \\
\hline UP_TISSUE & Umbilical cord blood & 197 & 0.17 & $5.14 \mathrm{E}-08$ \\
\hline UP_TISSUE & Mammary gland & 240 & 0.21 & $6.05 \mathrm{E}-08$ \\
\hline UP_TISSUE & Ovary & 452 & 0.40 & 4.35E-07 \\
\hline UP_TISSUE & Kidney & 765 & 0.67 & $1.81 \mathrm{E}-06$ \\
\hline UP_TISSUE & Pancreas & 519 & 0.46 & 4.43E-06 \\
\hline UP_TISSUE & B-cell & 160 & 0.14 & $6.34 \mathrm{E}-05$ \\
\hline UP_TISSUE & Teratocarcinoma & 297 & 0.26 & 0.000105 \\
\hline UP_TISSUE & Adipose tissue & 108 & 0.09 & 0.000142 \\
\hline UP_TISSUE & Human small intestine & 51 & 0.04 & 0.001389 \\
\hline UP_TISSUE & Melanoma & 176 & 0.15 & 0.001846 \\
\hline UP_TISSUE & Leukemia & 46 & 0.04 & 0.001979 \\
\hline UP_TISSUE & Keratinocyte & 80 & 0.07 & 0.003529 \\
\hline UP_TISSUE & Ovarian carcinoma & 90 & 0.08 & 0.00707 \\
\hline UP_TISSUE & Fetal kidney & 106 & 0.09 & 0.007677 \\
\hline UP_TISSUE & Renal cell carcinoma & 42 & 0.04 & 0.008965 \\
\hline UP_TISSUE & Umbilical vein & 27 & 0.02 & 0.008996 \\
\hline UP_TISSUE & Pituitary & 86 & 0.08 & 0.010397 \\
\hline UP_TISSUE & Bone & 42 & 0.04 & 0.014 \\
\hline UP_TISSUE & Skeletal muscle & 295 & 0.26 & 0.014765 \\
\hline UP_TISSUE & Endometrium carcinoma cell line & 19 & 0.02 & 0.020668 \\
\hline UP_TISSUE & Embryonic kidney & 48 & 0.04 & 0.021149 \\
\hline UP_TISSUE & Bladder & 48 & 0.04 & 0.021149 \\
\hline UP_TISSUE & Hepatoma & 128 & 0.11 & 0.021469 \\
\hline
\end{tabular}

Table 6 mRNAs expressed in a tissue-specific manner (Continued)

\begin{tabular}{lllll}
\hline UP_TISSUE & Embryo & 183 & 0.16 & 0.026251 \\
UP_TISSUE & Mammary carcinoma & 59 & 0.05 & 0.033882 \\
UP_TISSUE & Breast & 53 & 0.05 & 0.036028 \\
UP_TISSUE & Hypothalamus & 73 & 0.06 & 0.036155 \\
UP_TISSUE & Dendritic cell & 49 & 0.04 & 0.041269 \\
UP_TISSUE & Fetal brain & 391 & 0.34 & 0.041334 \\
UP_TISSUE & Carcinoma & 33 & 0.03 & 0.050043 \\
\hline
\end{tabular}

transforming growth factor-beta (TGF- $\beta$ ) signaling pathway [46]. High-temperature requirement A3 (HtrA3) inhibits BMP-4, BMP-2 and TGF- $\beta 1$ signaling [47]. Lactoferrin (LTF) functions in inflammation [48]. Myostatin (MSTN) was a negative regulator of myogenesis and has been implicated in the regulation of adiposity and controlling the structure and function of tendons [49]. IGFBP-7 acts through autocrine/paracrine pathways to inhibit BRAF-MEK-ERK signaling and induces senescence and apoptosis in cells containing the BRAF oncogene [50]. Additionally, IGFBP-7 inhibits cell growth and induces apoptosis in RKO and SW620 cells [51]. Confirmation of the presence of these 10 proteins in porcine milk exosomes suggests a possible function in the regulation of immunity, cell proliferation and possibly other pathways.

Table 7 Proteins expressed in a tissue-specific manner

\begin{tabular}{lllll}
\hline Category & Term & Count & $\%$ & Benjamini \\
\hline UP_TISSUE & Plasma & 73 & 1.22 & $3.36 \mathrm{E}-52$ \\
UP_TISSUE & Liver & 138 & 2.30 & $3.01 \mathrm{E}-31$ \\
UP_TISSUE & Milk & 17 & 0.28 & $2.57 \mathrm{E}-16$ \\
UP_TISSUE & Fetal brain cortex & 32 & 0.53 & $6.22 \mathrm{E}-15$ \\
UP_TISSUE & Cajal-Retzius cell & 30 & 0.50 & $2.98 \mathrm{E}-14$ \\
UP_TISSUE & Bile & 11 & 0.18 & $6.73 \mathrm{E}-10$ \\
UP_TISSUE & Placenta & 128 & 2.13 & $8.25 \mathrm{E}-09$ \\
UP_TISSUE & Urine & 10 & 0.17 & $1.45 \mathrm{E}-07$ \\
UP_TISSUE & Saliva & 12 & 0.20 & $6.37 \mathrm{E}-07$ \\
UP_TISSUE & Skin & 75 & 1.25 & $5.48 \mathrm{E}-06$ \\
UP_TISSUE & Platelet & 34 & 0.57 & $7.73 \mathrm{E}-06$ \\
UP_TISSUE & Neutrophil & 7 & 0.12 & 0.000105 \\
UP_TISSUE & Pancreas & 44 & 0.73 & 0.000382 \\
UP_TISSUE & Mammary gland & 24 & 0.40 & 0.000715 \\
UP_TISSUE & B-cell lymphoma & 12 & 0.20 & 0.002124 \\
UP_TISSUE & Blood & 29 & 0.48 & 0.021296 \\
UP_TISSUE & Adipose tissue & 12 & 0.20 & 0.024482 \\
UP_TISSUE & Colon & 43 & 0.72 & 0.025496 \\
UP_TISSUE & Ovary & 32 & 0.53 & 0.047235 \\
\hline
\end{tabular}




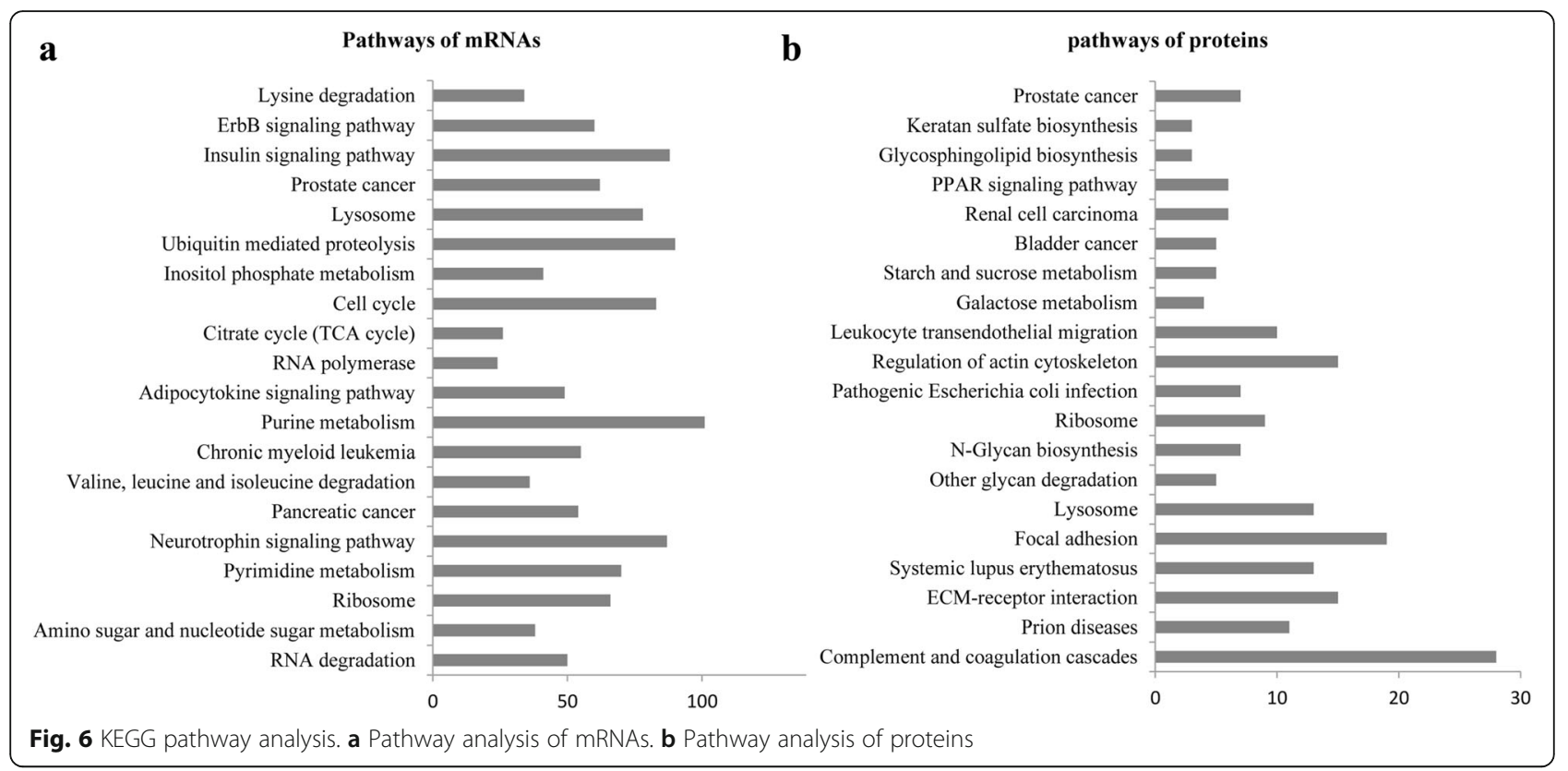

All previously reported exosomal proteins were cytosolic, and many of them were associated with the plasma membrane or membranes of endocytic compartments [7]. Most of the genes and proteins identified in the present study were relatived to cytoplasm or cytoplasmic GO terms (Tables 4 and 5). Analysis of GO, KEGG and COG annotations suggested that most porcine milk exosome genes and proteins might function in activation, immunity and cell cycle. KEGG analysis revealed that four pathways (ECM-receptor interaction, Focal adhesion, Regulation of actin cytoskeleton and Leukocyte transendothelial migration) were enriched in both bovine [29] and porcine milk exosomes (Fig. 6b, Additional file 8). Above results indicate a similar function in different species. Additionally, recent reports showed that the bovine milk exosomes were able to exert endocytosis and transferred their contained molecules to other cells [52]. In this study, proteins in porcine milk exosome were predicated to be involved in pathways of starch and sucrose metabolism, other glycan degradation, N-Glycan biosynthesis, galactose metabolism and glycosphingolipid biosynthesis (Fig. 6b, Additional file 8), it was deduced that porcine milk exosomes might transfer encapsulated materials, which could mediated by those proteins and played key roles in different physiological and pathological conditions. Meanwhile, the KEGG analysis of mRNAs showed lots of genes enriched in Purine metabolism, Pyrimidine metabolism, Insulin signaling pathway, Cell cycle and RNA degradation pathways, which were different to predicated pathways in the KEGG analysis of porcine milk exosomes proteins.

It is reported the viral RNA (hepatitis C virus) was able to transfer to infected cells (plasmacytoid dendritic cells) and trigger an innate immune response, depending on membrane vesicle trafficking [53]. The glioblastoma cells derived-exosome could deliver a specific mRNA transcript to endothelia cells followed by generating functional proteins for patients [54]. When incubated with NIH-3 T3 cells, milk-derived microvesicles could transfer bovine milk related transcripts to living cells and affect the calf's gastrointestinal development and immune systems [6]. Additionally, recent reports showed that bovine milk exosomes can be uptaken by endocytosis, depending on cell exosome surface glycoproteins [52].The uptaking exosome further affected gene expression [55]. And exosome can also be incorporated into differentiated human cells with containing RNA. These data collectively indicate the exosomes could not only deliver the encapsulated miRNAs, mRNAs and proteins to recipient cells, but also make their specific functions on immunity, thereafter play a key role in different physiological and pathological conditions. Our results provided extensively mRNAs and proteins data, which are beneficial to understand how milk regulates health and development of newborns by exosomes.

\section{Conclusions}

In this study, we identified 16,304 mRNAs and 639 proteins in porcine milk exosomes by RNA-sequencing and proteomic analysis, and many of mRNAs and proteins were predicted to be involved in immunity, proliferation and cellular signaling, which would be closely associated with piglets development and healthy. These findings provided a large amount of informations and contributed to increased understanding of the role of genes and proteins in milk exosomes, and build a foundation for future studies on their physiological functions and regulatory mechanisms. 


\section{Additional files}

\begin{abstract}
Additional file 1: mRNA expression. (XLSX $1186 \mathrm{~kb}$ )
Additional file 2: Novel transcripts. (XLSX $184 \mathrm{~kb}$ )

Additional file 3: Different top 50 mRNAs expression. (XLSX 20 kb)

Additional file 4: The 639 identified proteins analysis. (XLSX 400 kb)

Additional file 5: Figure S1. Peptide length distribution of identified proteins. $a, b, c, d$, and e represent the peptide length distribution of 10 , $13,6,8$, and Sus Scrofa proteins, respectively. (TIFF $1171 \mathrm{~kb}$ )
\end{abstract}

Additional file 6: Figure S2. Peptide and spectrogram distribution of identified proteins. a, b, c, d, and e represent the peptide and spectrogram distribution of 10, 13, 6, 8, and Sus_Scrofa proteins, respectively. (TIFF $942 \mathrm{~kb}$ )

Additional file 7: Figure S3. Distribution of protein sequences coverage. a, b, c, d, and e represent 10, 13, 6, 8, and Sus_Scrofa, respectively. (TIFF $1199 \mathrm{~kb}$ )

Additional file 8: Proteins bioinformatics analysis. (XLSX 28 kb)

Additional file 9: Figure S4. COG annotation of identified proteins. a, b, c, and d represent 10,13,6, and 8, respectively. (TIFF $1251 \mathrm{~kb}$ )

Additional file 10: mRNAs bioinformatics analysis.xlsx. (XLSX 218 kb)

\section{Abbreviations}

ACN: Acetonitrile; ACTC1: Alpha-cardiac actin one; ACTN2: Alpha-actin two; ACTN4: Alpha-actin four; AGC: Automatic gain control; BCA: Bicinchoninic acid; BMP-2: Bone morphogenetic protein 2; BMP4: Bone morphogenetic protein 4; BP: Biological Process; CC: Cellular Component; CD24: Tetraspan-integrin complexes 24; CD63: Tetraspanintegrin complexes 63; CD9: Tetraspan-integrin complexes 24; COG: Cluster of Orthologous Groups; CSN1S1: Casein alpha s1; CSN2: Beta-casein; CSN3: K-casein; CTGF: Connective tissue growth factor; Cyr61: Cysteine-rich protein 61; DTT: DL-Dithiothreitol; EEF1A1: Elongation factor 1 alpha-1; EGF: Epidermal growth factor; FABP3: Fatty-acid binding protein 3; FASN: Fatty acid synthase; FDR: False discovery rate; GO: Gene Ontology; HCD: High-energy collision dissociation; HRP: Horseradish Peroxidase; Hsp70: 70-kDa heatshock protein; HSPA 9: Heat shock 70kD protein 9; HSPA 90 B1: heat shock protein 90 kDa beta,member 1; HSPA13: Heat shock protein 70 kDa family, member 13; HSPA5: Heat shock 70 kDa protein 5; HSPB1: Heat shock 27 kDa protein 1; HSPCB: Heat shock 90kD protein beta; HTRA3: High-temperature requirement A3; IGFBP-7: Insulin-like growth factor binding protein 7; iTRAQ: Isobaric tag for relative and absolute quantitation; KEGG: Kyoto Encyclopedia of Genes and Genomes; LALBA: Lactalbumin alpha; LC-MS/MS: Liquid chromatography with tandem mass spectrometric; LTF: Lactoferrin; MF: Molecular Function; MFG: Milk fat globules; MFGE8: Milk fat globule-EGF factor 8; MFGM: Milk fat globule membrane; MGF: Mammary gland factor; MHC-class II: Major histocompatibility complex class II; miRNAs: MicroRNAs; mRNAs: Messager RNA; MSTN: Myostatin; NADH: Nicotinamide adenine dinucleotide; ncRNA: Noncoding RNA; PDGF: Platelet-derived growth factor; PDGFA: Platelet-derived growth factor A chain;

PMSF: Phenylmethanesulfonyl fluoride; QC: Quality control; RIPA: Radioimmunoprecipitation assay; RNA-Seq: RNA-sequencing; RPL18: 60S ribosomal subunit protein L18; RPLP1: Ribosomal phosphoprotein P1; RPS18: Ribosomal protein S18; rRNA: Ribosomal RNA; SPP1: Secreted phosphoprotein 1; TGFB-3: Transforming growth factor-beta 3; TGF$\beta 1$ : Transforming growth factor $\beta 1$; THBS1: Thrombospondin 1; TPT1: Translationally controlled tumor protein 1; TSG 101: Tumor susceptibility gene 101; UBA52: Ubiquitin A-52 ribosomal protein

\section{Acknowledgements}

None.

\section{Funding}

This work was supported by grants from the Key Project of Guangdong Provincial Nature Science Foundation (S2013020012766), National Nature Science Foundation of China, The National Key Research and Development
Program of China (2016YFD0500503) National Basic Research Program of China (973 Program, 2013CB127304), Hainan Provincial research institutes technology development key Project of China (grant number KYYS-2015-02) and Open subject of Hainan Provincial Key Laboratory of Tropical Animal Breeding and Disease Research (HNXMSYS201501). We thank the breeding farm of the Livestock Research Institute (Guangzhou, China) for providing milk samples.

\section{Availability of data and materials}

All the RNA-Seq data for analysis in this study have been deposited in https://www.ncbi.nlm.nih.gov/sra/ with an Accession No.: SSR 3436404. And the proteomics data were deposited in https://mynotebook.labarchives.com/ with a DOI: $10.6070 / \mathrm{H} 42 \mathrm{~J} 68 \times 8$.

\section{Authors' contrib}

TC, QX, JS carried out the proteins and mRNA sequencing and data analysis, and participated in drafted the manuscript. XC, RS carried out the Western blotting and q-PCR. GS, SW participated in the sample collected. XZ, NW performed the raw data analysis. RY, QJ and YZ conceived of the study, and participated in its design and coordination and helped to draft the manuscript. All authors read and approved the final manuscript.

\section{Competing interests}

The authors declare that they have no competing interests.

\section{Consent for publication}

Not applicable.

\section{Ethics approval}

The samples collected were according to the guidelines of Guangdong Province on the Review of Welfare and Ethics of Laboratory Animals approved by the Guangdong Province Administration Office of Laboratory Animals (GPAOLA). And the procedures were as the protocol of SCAU-AEC-2010-0416 approved by the Animal Ethics Committee of South China Agricultural University.

\section{Publisher's Note}

Springer Nature remains neutral with regard to jurisdictional claims in published maps and institutional affiliations.

\section{Author details}

${ }^{1}$ National Engineering Research Center For Breeding Swine Industry, Guandong Provincial Key Laboratory of Agro-Animal Genomics and Molecular Breeding, Guandong Province Research Center of Woody Forage Engineering and Technology, South China Agricultural University, 483 Wushan Road, Guangzhou 510642, China. ${ }^{2}$ Institute of Animal Science and Veterinary Medicine, Hainan Academy of Agricultural Sciences, Haikou 571100, China.

Received: 27 April 2016 Accepted: 3 April 2017

Published online: 13 April 2017

\section{References}

1. Gartner LM, Morton J, Lawrence RA, Naylor AJ, O'Hare D, Schanler RJ, Eidelman Al. Breastfeeding and the use of human milk. Pediatrics. 2005; 115(2):496-506.

2. Armogida SA, Yannaras NM, Melton AL, Srivastava MD. Identification and quantification of innate immune system mediators in human breast milk. In: Allergy and asthma proceedings: 2004: OceanSide publications, inc, vol. 2004. p. 297-304.

3. Kramer MS, Chalmers B, Hodnett ED, Sevkovskaya Z, Dzikovich I, Shapiro S, Collet J-P, Vanilovich I, Mezen I, Ducruet T. Promotion of breastfeeding intervention trial (PROBIT): a randomized trial in the Republic of Belarus. JAMA. 2001;285(4):413-20.

4. Kosaka $\mathrm{N}$, Izumi $\mathrm{H}$, Sekine $\mathrm{K}$, Ochiya $T$. microRNA as a new immuneregulatory agent in breast milk. Silence. 2010;1(1):7.

5. Høst A, Koletzko B, Dreborg S, Muraro A, Wahn U, Aggett P, Bresson J, Hernell O, Lafeber $\mathrm{H}$, Michaelsen K. Dietary products used in infants for treatment and prevention of food allergy. Joint statement of the European Society for Paediatric Allergology and Clinical Immunology (ESPACl) Committee on hypoallergenic formulas and the European Society for Paediatric Gastroenterology, Hepatology and nutrition (ESPGHAN) Committee on nutrition. Arch Dis Child. 1999;81(1):80-4 
6. Hata T, Murakami K, Nakatani H, Yamamoto Y, Matsuda T, Aoki N. Isolation of bovine milk-derived microvesicles carrying mRNAs and microRNAs. Biochem Biophys Res Commun. 2010;396(2):528-33.

7. Théry C, Zitvogel L, Amigorena S. Exosomes: composition, biogenesis and function. Nat Rev Immunol. 2002;2(8):569-79.

8. Théry C, Regnault A, Garin J, Wolfers J, Zitvogel L, Ricciardi-Castagnoli P, Raposo G, Amigorena S. Molecular characterization of dendritic cell-derived exosomes selective accumulation of the heat shock protein hsc73. J Cell Biol. 1999;147(3):599-610

9. Raposo G, Nijman HW, Stoorvogel W, Liejendekker R, Harding CV, Melief C, Geuze HJ. B lymphocytes secrete antigen-presenting vesicles. J Exp Med. 1996;183(3):1161-72.

10. Blanchard N, Lankar D, Faure F, Regnault A, Dumont C, Raposo G, Hivroz C. TCR activation of human $T$ cells induces the production of exosomes bearing the TCR/CD3/C complex. J Immunol. 2002;168(7):3235-41.

11. Raposo G, Tenza D, Mecheri S, Peronet R, Bonnerot C, Desaymard C. Accumulation of major histocompatibility complex class II molecules in mast cell secretory granules and their release upon degranulation. Mol Biol Cell. 1997;8(12):2631-45.

12. Wolfers J, Lozier A, Raposo G, Regnault A, Théry C, Masurier C, Flament C, Pouzieux S, Faure F, Tursz T. Tumor-derived exosomes are a source of shared tumor rejection antigens for CTL cross-priming. Nat Med. 2001;7(3):297-303.

13. Van Niel G, Raposo G, Candalh C, Boussac M, Hershberg R. Cerf-Bensussan N, Heyman M: intestinal epithelial cells secrete exosome-like vesicles. Gastroenterology. 2001;121(2):337-49.

14. Caby M-P, Lankar D, Vincendeau-Scherrer C, Raposo G, Bonnerot C. Exosomal-like vesicles are present in human blood plasma. Int Immunol. 2005;17(7):879-87.

15. Ogawa Y, Kanai-Azuma M, Akimoto Y, Kawakami H, Yanoshita R. Exosomelike vesicles with dipeptidyl peptidase IV in human saliva. Biol Pharm Bull. 2008;31(6):1059-62.

16. Admyre C, Johansson SM, Qazi KR, Filén J-J, Lahesmaa R, Norman M, Neve EP, Scheynius A, Gabrielsson S. Exosomes with immune modulatory features are present in human breast milk. J Immunol. 2007;179(3):1969-78.

17. Chen T, Xi Q-Y, Ye R-S, Cheng X, Qi Q-E, Wang S-B, Shu G, Wang L-N, Zhu X-T, Jiang Q-Y. Exploration of microRNAs in porcine milk exosomes. BMC Genomics. 2014;15(1):100.

18. Zhou Q, Li M, Wang X, Li Q, Wang T, Zhu Q, Zhou X, Wang X, Gao X, Li X. Immune-related microRNAs are abundant in breast milk exosomes. Int J Biol Sci. 2012;8(1):118.

19. Chen X, Gao C, Li H, Huang L, Sun Q, Dong Y, Tian C, Gao S, Dong H, Guan $D$. Identification and characterization of microRNAs in raw milk during different periods of lactation, commercial fluid, and powdered milk products. Cell Res. 2010;20(10):1128-37.

20. Gu Y, Li M, Wang T, Liang Y, Zhong Z, Wang X, Zhou Q, Chen L, Lang Q, He Z. Lactation-related MicroRNA expression profiles of porcine breast milk Exosomes. PLoS One. 2012:7(8):e43691.

21. Izumi H, Kosaka N, Shimizu T, Sekine K, Ochiya T, Takase M. Time-dependent expression profiles of microRNAs and mRNAs in rat milk whey. PLoS One. 2014; 9(2):e88843.

22. Izumi H, Kosaka N, Shimizu T, Sekine K, Ochiya T, Takase M. Bovine milk contains microRNA and messenger RNA that are stable under degradative conditions. J Dairy Sci. 2012;95(9):4831-41.

23. Izumi H, Kosaka N, Shimizu T, Sekine K, Ochiya T, Takase M. Purification of RNA from milk whey. In: Circulating MicroRNAs edn: Springer; 2013. p. 191-201.

24. Izumi H, Tsuda M, Sato Y, Kosaka N, Ochiya T, Iwamoto H, Namba K, Takeda Y. Bovine milk exosomes contain microRNA and mRNA and are taken up by human macrophages. J Dairy Sci. 2015;98(5):2920-33.

25. Lässer C, Alikhani VS, Ekström K, Eldh M, Paredes PT, Bossios A, Sjöstrand M, Gabrielsson S, Lötvall J, Valadi H. Human saliva, plasma and breast milk exosomes contain RNA: uptake by macrophages. J Transl Med. 2011;9(1):9.

26. Campanella C, Bavisotto CC, Gammazza AM, Nikolic D, Rappa F, David S, Cappello F, Bucchieri F, Fais S: Exosomal heat shock proteins as new players in tumour cell-to-cell communication. 2014

27. Keller S, Ridinger J, Rupp A-K, Janssen JW, Altevogt P. Body fluid derived exosomes as a novel template for clinical diagnostics. J Transl Med. 2011;9(86):240.

28. Torregrosa Paredes P, Gutzeit C, Johansson S, Admyre C, Stenius F, Alm J, Scheynius A, Gabrielsson S. Differences in exosome populations in human breast milk in relation to allergic sensitization and lifestyle. Allergy. 2014;69(4):463-71.

29. Reinhardt TA, Lippolis JD, Nonnecke BJ, Sacco RE. Bovine milk exosome proteome. J Proteome. 2012;75(5):1486-92.

30. Reinhardt TA, Sacco RE, Nonnecke BJ, Lippolis JD. Bovine milk proteome: quantitative changes in normal milk exosomes, milk fat globule membranes and whey proteomes resulting from Staphylococcus aureus mastitis. J Proteome. 2013; 82:141-54.

31. Chen C, Ai H, Ren J, Li W, Li P, Qiao R, Ouyang J, Yang M, Ma J, Huang L. A global view of porcine transcriptome in three tissues from a full-sib pair with extreme phenotypes in growth and fat deposition by paired-end RNA sequencing. BMC Genomics. 2011;12(1):448.

32. Li R, Yu C, Li Y, Lam T-W, Yiu S-M, Kristiansen K, Wang J. SOAP2: an improved ultrafast tool for short read alignment. Bioinformatics. 2009;25(15):1966-7.

33. Mortazavi A, Williams BA, McCue $K$, Schaeffer $L$, Wold B. Mapping and quantifying mammalian transcriptomes by RNA-Seq. Nat Methods. 2008:5(7):621-8.

34. Ye R-S, Xi Q-Y, Qi Q, Cheng X, Chen T, Li H, Kallon S, Shu G, Wang S-B, Jiang Q-Y. Differentially expressed miRNAs after $\mathrm{GnRH}$ treatment and their potential roles in FSH regulation in porcine anterior pituitary cell. PLoS One. 2013;8(2):e57156.

35. Stoscheck CM. [6] Quantitation of protein. Methods Enzymol. 1990;182:50-68.

36. Théry C, Boussac M, Véron P, Ricciardi-Castagnoli P, Raposo G, Garin J, Amigorena S. Proteomic analysis of dendritic cell-derived exosomes: a secreted subcellular compartment distinct from apoptotic vesicles. Immunol. 2001;166(12):7309-18.

37. Maningat PD, Sen P, Rijnkels M, Sunehag AL, Hadsell DL, Bray M, Haymond MW. Gene expression in the human mammary epithelium during lactation: the milk fat globule transcriptome. Physiol Genomics. 2009;37(1):12-22.

38. Guescini M, Genedani S, Stocchi V, Agnati LF. Astrocytes and Glioblastoma cells release exosomes carrying mtDNA. J Neural Transm. 2010;117(1):1-4.

39. Mathivanan S, Simpson RJ. ExoCarta: a compendium of exosomal proteins and RNA. Proteomics. 2009;9(21):4997-5000

40. Mather $\mathrm{H}$. A review and proposed nomenclature for major proteins of the milk-fat globule membrane. J Dairy Sci. 2000;83(2):203-47.

41. Théry C, Ostrowski M, Segura E. Membrane vesicles as conveyors of immune responses. Nat Rev Immunol. 2009;9(8):581-93.

42. Mathivanan S, Ji H, Simpson RJ. Exosomes: extracellular organelles important in intercellular communication. J Proteome. 2010;73(10):1907-20.

43. Bobrie A, Colombo M, Raposo G, Théry C. Exosome secretion: molecular mechanisms and roles in immune responses. Traffic. 2011;12(12):1659-68.

44. Gilbertson DG, Duff ME, West JW, Kelly JD, Sheppard PO, Hofstrand PD, Gao Z, Shoemaker K, Bukowski TR, Moore M. Platelet-derived growth factor C (PDGF-C), a novel growth factor that binds to PDGF a and $\beta$ receptor. J Biol Chem. 2001:276(29):27406-14.

45. Riese DJ, Stern DF. Specificity within the EGF family/ErbB receptor family signaling network. BioEssays. 1998;20(1):41-8.

46. Zhou Z-Q, Cao W-H, Xie J-J, Lin J, Shen Z-Y, Zhang Q-Y, Shen J-H, Xu L-Y, Li E-M. Expression and prognostic significance of THBS1, Cyr61 and CTGF in esophageal squamous cell carcinoma. BMC Cancer. 2009;9(1):291.

47. Tocharus J, Tsuchiya A, Kajikawa M, Ueta Y, Oka C, Kawaichi M. Developmentally regulated expression of mouse $\mathrm{HtrA} 3$ and its role as an inhibitor of TGF- $\beta$ signaling. Develop Growth Differ. 2004;46(3):257-74.

48. Britigan BE, Serody JS, Cohen MS. The role of lactoferrin as an antiinflammatory molecule. Lactoferrin edn: Springer; 1994. p. 143-56.

49. Hickford J, Forrest R, Zhou H, Fang Q, Han J, Frampton C, Horrell A. Polymorphisms in the ovine myostatin gene (MSTN) and their association with growth and carcass traits in New Zealand Romney sheep. Anim Genet. 2010;41(1):64-72.

50. Wajapeyee N, Serra RW, Zhu X, Mahalingam M, Green MR. Oncogenic BRAF induces senescence and apoptosis through pathways mediated by the secreted protein IGFBP7. Cell. 2008;132(3):363-74.

51. Ruan W, Xu E, Xu F, Ma Y, Deng H, Huang Q, Lv B, Hu H, Lin J, Cui J. IGFBP7 plays a potential tumor suppressor role in colorectal carcinogenesis. Cancer Biol Ther. 2007;6(3):354-9.

52. Wolf T, Baier SR, Zempleni J: The Intestinal Transport of Bovine Milk Exosomes Is Mediated by Endocytosis in Human Colon Carcinoma Caco-2 Cells and Rat Small Intestinal IEC-6 Cells. J Nutr 2015:jn218586.

53. Dreux M, Garaigorta U, Boyd B, Décembre E, Chung J, Whitten-Bauer C, Wieland S, Chisari FV. Short-range exosomal transfer of viral RNA from infected cells to plasmacytoid dendritic cells triggers innate immunity. Cell Host Microbe. 2012;12(4):558-70.

54. Skog J, Würdinger T, van Rijn S, Meijer DH, Gainche L, Curry WT, Carter BS, Krichevsky AM, Breakefield XO. Glioblastoma microvesicles transport RNA and proteins that promote tumour growth and provide diagnostic biomarkers. Nat Cell Biol. 2008;10(12):1470-6.

55. Lonnerdal B, Du X, Liao Y, Li J. Human milk exosomes resist digestion in vitro and are internalized by human intestinal cells. FASEB J. 2015;29(1 Supplement):121.123. 